\title{
Self-concepts and demographic characteristics of battered women in Gauteng, South Africa
}

\author{
ES Idemudia, PhD \\ Department of Psychology, University of Limpopo (Turfloop Campus).
}

$\underline{\text { Kev words }}$

IPV, GBV, Abuse, Battering, Women

\section{Correspondence address}

Prof ES Idemudia

POBox 1106 ,

Sovenga, 0727

South Africa.

Tel : (015) 268-2944

Fax : (015) 268-2944

Email : sundayidemudia@yahoo.com or sidemudia@ul.ac.za

\section{Abstract: Curationis 32 (1): 45-51}

In South Africa, studies have shown that one in every four women are abused or battered. Put graphically, 25\% of women in the Republic of South Africa (RSA) are assaulted by their boyfriend/partner or husband and a woman suffer battering on average of 39 times before she seeks outside help. Woman battering can leave women abused, distressed, create fear, limits behaviour, cause psychological damage and physical harms and very often breaks down self-esteem and leaves the individual self-incompetent. Hence the need to understand how women who have been abused rate their pre and post abuse self-concepts, how their demographic characteristics influence their self-concepts and also understand their attitude towards their abuser.

Through in-depth interviews using a questionnaire, data were collected from 150 randomly selected abused women attending a respite centre located in Johannesburg. Age of women ranged from 16 years to 49 years with a mean age of 32.2 $(\mathrm{SD}=8.27$ ). Abuse or being battered in this study is defined as "women who have been emotionally abused or physically beaten by husband/boyfriend with blows, slapped, kicked and have experienced these over three times in a single relationship.

The study was anchored on a three research questions. Results showed that before abuse, women rated themselves positively $(\mathrm{X}$ bar $=82.4)$ and negatively after abuse $(X$ bar $=69.9)$. The study showed a huge drop in self-concept change $(X$ bar $=23.9)$ after abuse. At a pre-abuse level, women generally rated themselves positively on almost all dimensions and negatively after abuse on almost all bi-polar items. The study also found that demographics of abused women such as marital status $\left(\mathrm{C}^{2}(1\right.$, $\mathrm{N}=149)=7.30, \mathrm{P}<.01)$, educational level $\left(\mathrm{C}^{2}(1, \mathrm{~N}=149)=15.89, \mathrm{P}<.001\right)$, duration of abuse $\left(C^{2}(1, N=149)=12.71, P<.002\right)$, and nature of abuse $\left(C^{2}(1, N=149)=4.502, P\right.$ $<.05)$ do influence self-concepts of abused women. Age of women was not significant. Finally, results also indicate that majority of the women have negative attitude towards their abuser $\left(\mathrm{C}^{2}(1, \mathrm{~N}=149)=4.051, \mathrm{P}<.05\right)$. The abuser was described negatively as cold, slow, passive, weak, sick, tense, unpredictable, sad, dangerous, ignorant and bad. Surprisingly, the abuser was also described as rich, wise, clean and valuable.

These findings have significant practical implications for intimate partner violence or Gender-based violence and the health and psychological outcomes for battered women. The study also suggests the need for more research in this direction and a need for culturally relevant programmes to help women in abusive relationships and in addition help the abusers deal with myths that have cultural relevance to factors maintaining battering. 


\section{Introduction and background}

In South Africa, studies (De Sousa, 1992: 1, POWA, 2006:2) reveal that 1 in every 4 South African women or put graphically, $25 \%$ of women in the Republic of South Africa (RSA) are assaulted by their boyfriend/partner or husband and a woman suffers battering on average of 39 times before she seeks outside help. Woman battering can take many forms: physical, sexual, psychological and or a combination of all these.

In Africa, the story is not different. Violence against women is also a widespread problem. Odunjirin, (1993) and Wood \& Jewkes (1997) reveal a prevalent rate of $46 \%$ (Uganda), $60 \%$ (Tanzania), $42 \%$ (Kenya) $40 \%$ (Zambia), and $81 \%$ (Nigeria).

In the United States, intimate partner violence remains a prevalent, dangerous and a serious public health problem: 850, 000-1, 5 million women are raped or physically assaulted by a partner each year and the lifetime prevalence of physical assault by a partner is $22 \%$ (Tjaden \& Thoennes, 2000:8). Recent annual estimates in the US alone indicate that over 8.7 million women are battered by husbands, boyfriends, and other intimate partners (Roberts, 2002: 4; Roberts and Roberts, 2005: 6) or graphically put, in every nine seconds, somewhere in the United States, a woman is battered by someone she knows (Roberts 2005:13).

In addition, approximately one in three homicides in the US are committed by intimate partners (Paulozzi, Saltman, Thompson, \& Holmgreen, 2001: 7). Injuries sustained by women ranging in age from 15 to 44 occur because of intimate partner violence (IPV) more often than cancer, motor vehicles accidents, and violence by strangers or acquaintances (Boes 1998: 5).

In non-western societies, relationships are organized in culturally interdependent networks. Matsumoto (2001) and Wang (2006) have shown the significant impact of culture on self in interdependent (Asians/Africans) societies, which are embedded in group and social relations. According to Baumeister (1999), the self is a psycho- logical rather than a physical being, and it is one that contains thought, feelings, and attitudes, one that is socially validated and holds multiple places in the matrix of social relationships. In the words of Wang (2006), "Asian (and African) cultures prominence is given to interrelatedness and collectivity that governs the social network and as such individual tends to perceive themselves focusing on their social roles and relationships". For this reason, many battered women do not make criminal complains due to cultural beliefs and therefore stay in battering relationships for many years.

Cultural beliefs may exacerbate the effects of domestic violence because women may stay in an abusive relationship longer to protect the family's privacy. African women are socialized to believe that the family is of paramount importance and that males are known to be dominant as heads of households while the women serve as caretakers of the family. Deviating from this belief system may portray a woman as bad wife or bad mother. In many African societies, families and communities perceive reporting abuse by a spouse negatively particularly if they are married. According to Odunjirin, (1993), cultural mores against reporting abuse make women endure the relationships and hence suffer years of abuse and violence.

According to Campbell and Lewandowski (1997), McCauley et al (1995), Thompson, Kaslow \& Kingree, (2002), and Valentine, Roberts and Burgess (1998) battering of women has serious and long-term impact on the woman's emotional wellbeing and is likely to cause symptoms of depression and anxiety, as well as suicidal thoughts and low self-esteem.

Woman battering can leave women abused, distressed, create fear, limits behaviour, cause psychological damage and physical harms and very often breaks down self-esteem and leaves the individual self-incompetent. Self-competency is about an individual's strong belief that he/she is capable. When a woman is self-incompetent, she may commit suicide. According to Heise (1993), one out of every four suicide attempts by women is preceded by abuse and this abuse may in turn cause aggression and depression in their children. Unfortunately studies on selfconcepts of battered women are under investigated in Africa.

According to Connelly (1999) and Greenberg and Bolger (2001) to be daily assaulted and physically abused amounts to a kind of suffering which leave the individual broken, shattered, empty and lost. Fears and altered beliefs emerge from an experience of suffering, together with related emotions of distress, misery, anguish, agony, agitation, unhappiness, torment, anger, frustration, hopelessness, destruction and worry. For Morse (2001) the nature of suffering involves loss: for example the loss of dignity, the loss of self, etc. Such loses often involve discomfort, anguish, distress, anxiety etc.

Unfortunately, while research in psychology has discussed and studied self-concepts, it has not done so in relation to comparing pre/post self concepts of women and the relationship of these self-concepts to demographic characteristics of these women who experience interpersonal violence. Also, this comparison has not been investigated in Africa. Roberts (1987), Roberts (2002), Maxwell, Garner and Fagan (2001) and Campbell and Lewandowski, (1997) have linked batterer demographics and psychosocial variables to domestic violence chronicity and injury severity and health outcomes but no studies have investigated before and after abuse self-concepts of battered women and the attitude these women have towards their batterer.

In addition, because cultural mores against reporting of abuse make it difficult to assess prevalence accurately, there are knowledge gaps of women who experience battering in intimate partner relationships. Understanding these differences in self-concepts may influence public policy and contribute to the design of culturally appropriate strategies for prevention and intervention. Unfortunately, many Non-Governmental Organizations (NGOs) who work with these women only give short-term respite services and psychological services offered, focuses on symptom report thereby neglecting the relevance of self-concept in relation to the abuse. According to Faizullaev (2006), the self 
is crucial for personal integrity and identity for individual cohesiveness and it plays a significant role in the organization of individual behaviour and psychological processes such as perception, memory attention, emotion and motivation. Research on how battered women describe themselves are scarce, hence there are knowledge gaps. To bridge this gap, this study proposed three research questions: (1) would there be a difference between pre-abuse and post-abuse self-concepts of battered women? (2) Will demographics of women, such as age, marital status, educational level, type of abuse and duration of abuse influence self-concept change of battered women? (3) Will attitude of abused women towards their abuser be positive or negative? Abuse and battered are used interchangeably in this study.

\section{Methodology \\ Participants}

Through in-depth interviews, one hundred and fifty (150) women attending respite centres and who have reported abuse or being battered were randomly selected for the study after an Institutional Review Board (IRB) approval. Entry criteria include being above age 16 years; readiness to participate with approved consent, history of abuse of more than three cases, within a year and must have reported the problem to warrant concern. All the participants gave their consent which they read or was read to them on confidentiality, anonymity, benefits of study, and privacy. Age of women range from 16 years to 49 years with a mean age of $32.2(\mathrm{SD}=8.27)$. Abuse or being battered in this study is defined as "women who have been emotionally abused or physically beaten by husband/boyfriend with blows, slapped, kicked and have experienced these over three times in a single relationship".

All the participants were women receiving counselling from the trauma counsellor or social workers unit respite centre in Johannesburg. Participants were randomly selected using a table of random numbers (every third person) from the list of patients in the Centre. All participants were residents in Johannesburg and its surrounding areas. The Non Governmental Organization (NGO) assists women who have been battered and have left these relationships and those still in an abusive relationships. The services of the NGO include individual and group support to survivors of gender based violence, individual and group support to perpetrators of gender based violence, initiating and supporting economically viable micro enterprises for survivors of gender based violence.

\section{Instrument}

A questionnaire was used to collect data from respondents. The questionnaire had four sections: A, B, C and D. Section A consist of demographic questions such as age, nature and type of abuse etc. Section B contained items measuring attitude towards the abuser. These were 17 items derived from Osgood's list of Semantic differential items, (Osgood \& Suci, 1955: 2). Response format was based on the bipolar differential with 7 options format. Answers ranged from 1-7. With 1 being "much", 2 "moderately", and 3 "slightly negative", 4 "indifference or both apply equally", and 5 "slightly ",6 "moderately" and 7 "very much positive". Sections C and D contained the same worded bipolar 21 items measuring pre-and post abuse self-concepts also derived from Osgood's list of bipolar items with similar response format of 1-7.

Participants were asked to rate their self-concepts before they experienced battering from their boyfriends/husbands and after they have experienced abuse and check whether their views were very much, moderately, and slightly negative, indifference (which is neither adjectives apply equally) and slightly, moderately and very much positive with each pair of adjectives on the scale. The participant indicated her rating by checking one of the seven spaces separating the word good from the word bad. If the participant thought the concept in question was good, she would check the space closest to the word good.

For example, participants were asked to rate their pre-abuse self-concept:

$$
\frac{\mathrm{Bad}}{1}-\frac{}{2}-\frac{\mathrm{Good}}{5}-\frac{}{6}
$$

This procedure was followed for each of the items. The response for each item scored according to categories with pre-assigned values of $1,2,3,4,5,6$ and 7 . The questions were framed in such a way that about half of the total number of statements, very much, moderately, slightly, indicated negative attitude to the left, thus were assigned scale values of 1,2 , and 3 while 4 served as neutral or both adjectives apply equally. The rest half of the scales fall to the right indicating positive attitude such as slightly, moderately and very much, and thus were assigned scale values of 5,6 , and 7 respectively. The evaluation dimension of the three scales has three factors: Evaluation, potency and activity. The evaluative factor has high loading such as badgood, worthless-valuable, dirty-clean, insincere-sincere, foolish-wise, ignorant-intelligent, dangerous-safe. The potency factor also comprises of sadhappy, poor-rich, unpredictable-predictable, tense-relaxed, sick-healthy, wcak-strong, delicate-rugged, and the activity factors such as passive-active, slow-fast and cold-warm. Same items have been used to measure attitude of the general population towards the mentally in Nigeria (Oyefeso, Osinowo and Idemudia 1989: 15). The items were validated for the battered women in South Africa. For the 17 attitude items, internal consistency (.73) and testretest of over four weeks $(.74)$ were adequate. Also, internal consistency for 21 self-concept items was .76 and a test-retest of over four weeks was .77 . Bipolar adjective scales are simple to use and are economical means for obtaining data on people's reactions and can be adapted for use for children and adults.

\section{Results}

For the first research question, student t-test was used to test the change in means for pre-abuse self-concepts and post-abuse self concepts of battered women and results showed a huge significant difference, $t(148)=23.9, P<001)$, (see fig 1).

From figure 1, mean scores of battered women showed positive self-concepts before they were abused $(\mathrm{X} \mathrm{bar}=82.4)$ compared to a negative self-concepts after abuse ( $\mathrm{X}$ bar $=69.9)$. The change $(\mathrm{X}$ bar $=23.9)$ in self-concepts was huge. At a pre-abuse level, women 
Pre and post abuse Self-Concepts of battered women

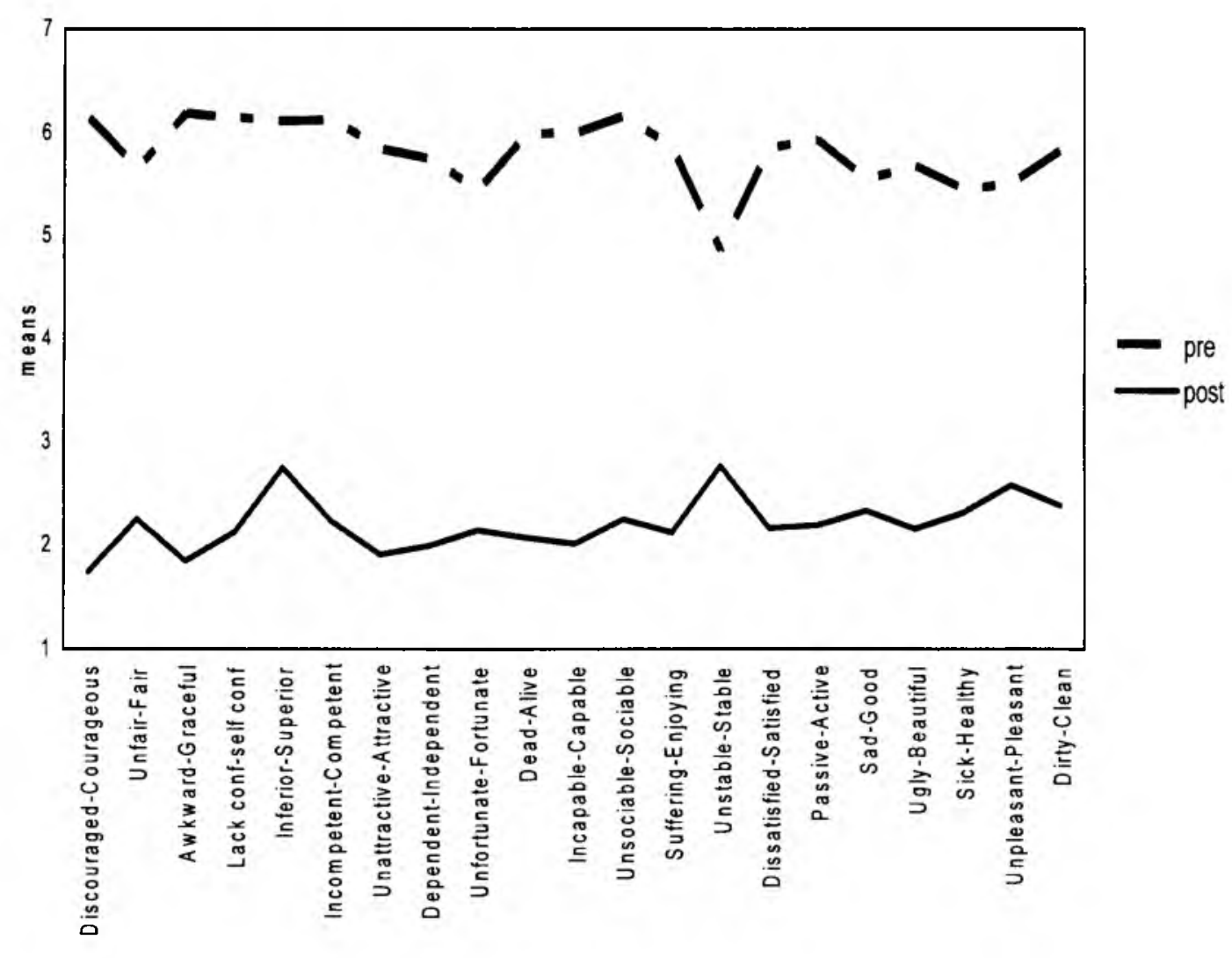

generally rated themselves positively on almost all dimensions: courageous, fair, graceful, superior, self-confident, competent, attractive, alive, capable, enjoying, satisfied, active, good, beautiful, healthy, pleasant and clean. Unfortunately, a post-abuse self-concept showed a negative rating such as unfair, awkward, lack self confident, inferior, incompetent, unattractive, dependent, unfortunate, dead, incapable, unsociable, suffering, dissatisfied, passive, sad, ugly, sick and unpleasant.

The second research question wanted to find out whether demographic characteristics of women such as age, marital status, educational level, type of abuse and duration of abuse would have any influence on self-concepts of women who are battered. This was tested with a chi-square $\left(\mathrm{C}^{2}\right)$ test. According to table 1 below, there were sig- nificant effects for marital status, $\mathrm{C}^{2}$ (1, $\mathrm{N}=149)=7.30, \mathrm{P}<.01$; Educational level, $\mathrm{C}^{2}(1, \mathrm{~N}=149)=15.89, \mathrm{P}<.001$; Duration of abuse, $C^{2}(1, N=149)=12.71$, $\mathrm{P}<.002$; Nature of abuse, $\mathrm{C}^{2}(1, \mathrm{~N}=149)$ $=4.502, \mathrm{P}<.05$; only age was not significant. In other words, married women reported more negative self-concepts than unmarried women, women with high school education reported more negative self-concepts than women with lower level of education, women with longer period of abuse had higher negative self-concepts than those with short period of abuse, battered women who experienced more of physical abuse reported more of negative selfconcepts than those who were psychologically abused.

The third research question wanted to know whether women who have been abused would have a positive or nega- tive attitude towards their abuser and this was also tested with a chi-square test and results showed a significant difference between women with positive and negative attitudes, $\mathrm{C}^{2}(1, \mathrm{~N}=$ $149)=4.051, P=<.05$. Majority (55) of the women $(37.0 \%)$ have negative attitudes compared to women with positive attitudes $(\mathrm{N}=22,(14.8 \%)$ toward their abuser (see fig 2). The abuser was described negatively as cold, slow, passive, weak, sick, tense, unpredictable, sad, dangerous, ignorant and bad. Surprisingly, the abuser was also described as rich, wise, clean and valuable.

\section{Discussion}

The study seeks to understand how women who have been abused rate their self-concepts (pre and post abuse), how their demographic char- 
attitude toward the perpetrator

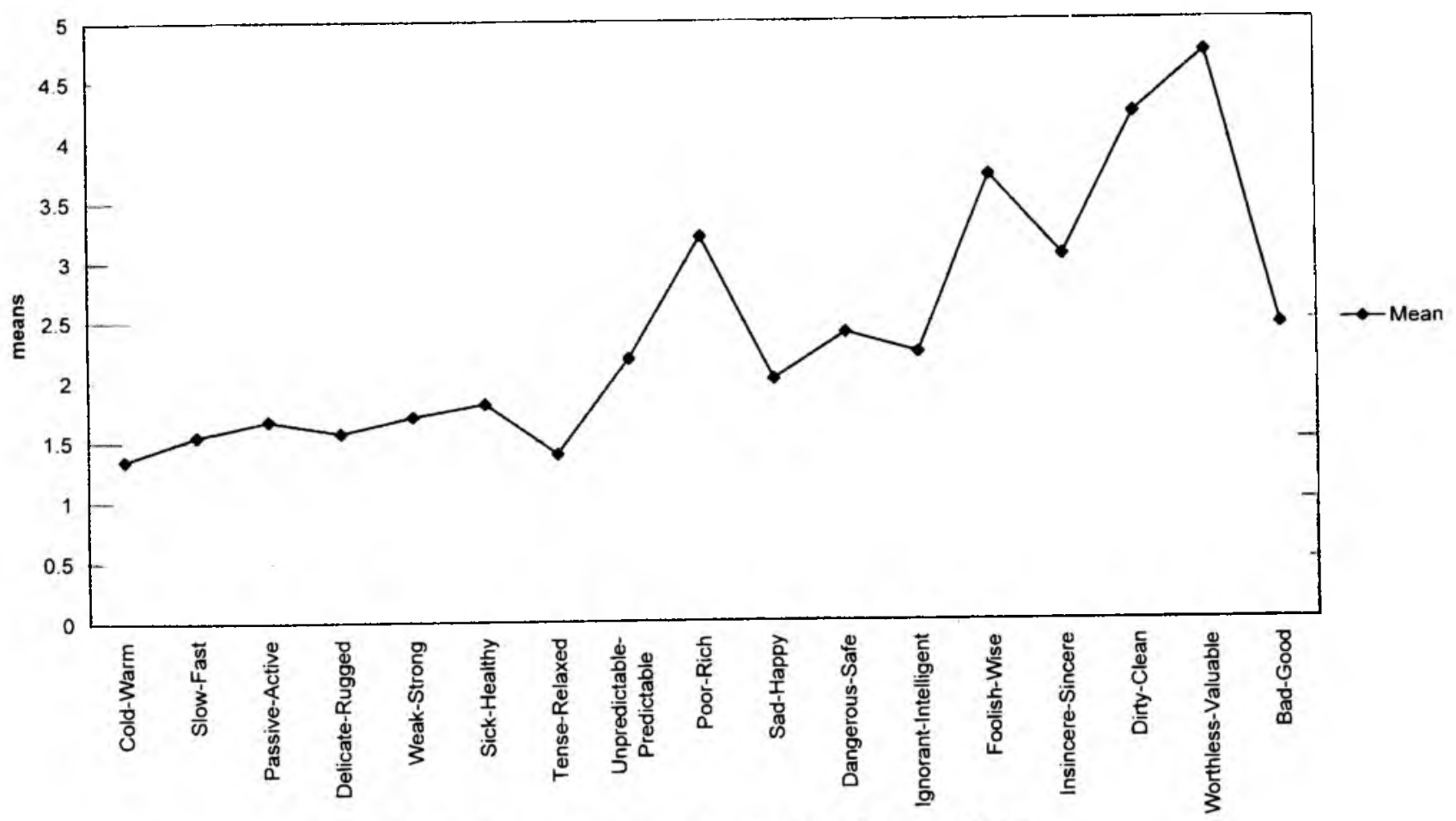

Attitude dimensions of abused women toward the perpetrator

Table 1: Comparison of demographic characteristics $\left(C^{2}\right)$ on self concepts of abused women

\begin{tabular}{|c|c|c|c|c|c|c|c|}
\hline Variables & & Negative change & Positive change & $\mathbf{N}$ & Total & $C^{2}$ value & $\mathbf{P}$ \\
\hline Age & $\begin{array}{l}\text { Young } \\
\text { Old }\end{array}$ & $\begin{array}{l}18(12.0) \\
77(51.7)\end{array}$ & $\begin{array}{l}16(10.7) \\
38(51.7)\end{array}$ & $\begin{array}{l}95 \\
54\end{array}$ & 149 & 2.23 & $\mathrm{~ns}$ \\
\hline Marital status & $\begin{array}{l}\text { Unmarried } \\
\text { Married }\end{array}$ & $\begin{array}{l}47(31.5) \\
39(26.2)\end{array}$ & $\begin{array}{l}48(32.2) \\
15(10.1)\end{array}$ & $\begin{array}{l}95 \\
54\end{array}$ & 149 & 7.30 & .01 \\
\hline Educational level & $\begin{array}{l}\leq \text { High Sch } \\
\geq \text { High Sch }\end{array}$ & $\begin{array}{l}67(44.9) \\
28(18.8)\end{array}$ & $\begin{array}{l}20(13.4) \\
34(22.9)\end{array}$ & $\begin{array}{l}95 \\
54\end{array}$ & 149 & 15.9 & .001 \\
\hline Duration of Abuse & $\begin{array}{l}\text { Short } \\
\text { Long }\end{array}$ & $\begin{array}{l}22(14.8) \\
73(48.9)\end{array}$ & $\begin{array}{l}28(18.8) \\
26(17.5)\end{array}$ & $\begin{array}{l}95 \\
54\end{array}$ & 149 & 12.7 & .002 \\
\hline Nature of Abuse & $\begin{array}{l}\text { Psychological } \\
\text { Physical }\end{array}$ & $\begin{array}{l}26(17.5) \\
69(46.3)\end{array}$ & $\begin{array}{l}24(16.1) \\
30(20.1)\end{array}$ & $\begin{array}{l}95 \\
54\end{array}$ & 149 & 4.50 & .05 \\
\hline
\end{tabular}

$\%$ in parenthesis

acteristics or attributes influence their self-concepts and also to understand the women's attitude towards their abuser. Three research questions were stated on which the study was anchored.

The first research question was sup- ported. Post-abuse self-concepts of battered women significantly became worse when compared to pre-abuse self-concepts. Unfortunately, battered women rated themselves negatively such as unfair, awkward, lack self confidence, inferior, incompetent, unattrac- tive, dependent, unfortunate, dead, incapable, unsociable, suffering, dissatisfied, passive, sad, ugly, sick and unpleasant. This finding supports the studies done by Campbell and Lewandowski, (1997), McCauley et al (1995), Valentine, Roberts, and Burgess, 
(1998), and Thompson, Kaslow and Kingree, (2002). This finding has implications for the study of Heise (1993) which found that one in every four suicide attempts by women is preceded by abuse and which may in fact cause aggression and depression in their children.

The second research question predicted that demographics of women, such as age, marital status, educational level, type of abuse and duration of abuse would significantly influence self-concept change of battered women. Results also showed significant effects for marital status, educational level, duration of abuse and nature of abuse. Age of participants was not significant. Since no studies have been done in this regard, studies were not evaluated for demographic variables. However, Roberts, (1987, 2002), and Maxwell, Garner and Fagan, (2001), reported demographics for batterers but not for the battered.

The third research question asked if attitude of abused women towards their abuser will be positive or negative. The abuser was described negatively on many of the bipolar concepts as cold, slow, passive, weak, sick, tense, unpredictable, sad, dangerous, ignorant and bad. The abuser was also described positively as rich, wise, clean and valuable. Again, there is lack of studies with self-concepts and battered or abused women hence studies were not reviewed. However, it is important to note that many of the abusers are seen to be rich, clean and valuable hence women may remain in their abusive relationship because of economic reasons.

\section{Conclusion}

From this study, the following conclusions are made:

- Women reported positive selfconcepts before they were abused. They rated themselves as courageous, fair, graceful, superior, self-confident, competent, attractive, alive, capable, enjoying, satisfied, active, good, beautiful, healthy, pleas ant and clean.

- Women rated themselves negatively after abuse. They rated themselves as unfair, awkward, lacking self-confident, inferior, incompetent, unattractive, dependent, unfortunate, dead, incapable, unsociable, suffering, dissatisfied, passive, sad, ugly, sick and unpleasant.

- There is no doubt that there are significant changes from positive self-concepts to negative self-concepts as a result of battering.

- Married women reported more negative self-concepts than unmarried women.

- Women with high school edu cation reported more negative self-concepts than women with lower level of education.

- Women with longer period of abuse reported more negative self-concepts than those with short period of abuse.

- Women who have been abused physically (slapping, blows, beatings) reported negative self-concepts than those who were psychologically or emotionally abused.

- Majority of the women have negative attitude towards the abuser. The abuser was described as cold, slow, sick, passive, weak, tense, unpredictable, sad, dangerous, ignorant and bad. The abuser was also described as rich, wise, clean and valuable.

- There was no significant difference of age of women and selfconcepts.

\section{Recommendations}

- $\quad$ Studies on IPV (Intimate Part ner Violence), Gender-based violence (GBV) and Woman battering (WB) are complex and therefore demands multifaceted solutions and these should include broadly: abuser and batterer variables, putting in place programmes to change at titude of men and women.

- $\quad$ Also, efforts should be made by Governments and NGOs to design culturally relevant programmes to help the battered and those battering deal with myths that have cultural rel evance to factors maintaining battering.

- $\quad$ Finally, research should be geared in this direction to en able researchers understand fully the dynamics of variables that are important in IPV and GBV.

\section{References}

BAUMEISTER, RF 1999: The nature and structure of the self: An overview. (In Baumeister RF, eds. 1999: The Self in social psychology. Philadephia: Psychology Press, p.1).

BOES, ME 1998: Battered women in emergency rooms: Emerging roles for the ER social worker and clinical nurse specialist. (In Roberts, AR, eds.1998: Battered women and their families: Intervention strategies and treatment programmes. New York: Springer, p. 205209).

CAMPBELL, JC \& LEWANDOWSKI, LA 1997: Mental and physical health effects of intimate partner violence on women and children. Psvchiatric Clinics of North America 20,353-374

CONNELLY, JE 1999: The tragedy of 'Why me, Doctor'? (In Mohrmann, ME \& Hanson, MJ, eds. 1999: Pain seeking understanding: Suffering, medicine and faith. Cleveland, OH: Pilgrim Press, p. 35-90).

DE SOUSA, JP 1992: Behind closed doors: Guidelines for battered women and raising community awareness. Cape Town: Catholics Welfare Bureau.

FAIZULLAEV, A 2006: Diplomacy and self. Diplomacy and Statecraft. 17, 497522.

GERSTENBERGER, ES\&SCHRAGE, W 1977: Suffering. Mashville, TS: Abingdon.

GREENBERG, LS \& BOLGER, E 2001: An emotional-focused approach to the overregulation of emotion and emotional pain. Psvchotherapv in Practice, $57(2), 197-211$.

HEISE, LL; PITANGUY, J \& GERMAIN, A 1993: Violence against women: the hidden health burden. Washington, DC: World Bank. \{World Bank discussion Papers, no.255\}

MATSUMOTO, D, eds. 2001: The 
handbook of culture and psychology. Oxford/New York: Oxford University Press.

MAXWELL, CD; GARNER, JH \& FAGAN, JA 2001: The effects of arrest on intimate partner violence: New evidence from the spouse assault replication programme. Washington, DC: U.S. Department of Justice. (Research in Brief: National Institute of Justice. Washington, DC: U.S. Department of Justice).

MCCAULEY, J; KERN, DE; KOLODNER, K; DILL, L; SCHROEDER, AF \& DECHANT, HK, et al 1995: The battering syndrome: Prevalence and clinical characteristics of domestic violence in primary care internal medicine patients. Annals of internal Medicine. 123, 737-746.

MEAD, G 1962: Mind, Self and Society. Chicago: The University of Chicago Press.

MORSE, JM 2001: Toward a praxis theory of suffering. Advances in Nursing Science. 24(1), 47-59.

ODUNJINRIN, O 1993: Wife battering in Nigeria. Int J Gynaecol Obstet. 41, 159-164.

OSGOOD, CE \& SUCI, GJ 1955: Factor analysis of meaning. Journal of Experimental Psvchology. 50, 325-338.

OYEFESO, A; OSINOWO, HO \& IDEMUDLA, ES 1989: Sex and Propinquity as Predictors of attitude towards the mentally ill among Nigerians. Indian Journal of Behaviour. 13, (3), 27-32.

PAULOZZI, LJ; SALTZMAN, LE; THOMPSON, MP \& HOLMGREEN, P 2001: Surveillance for homicide among intimate partners-United States, 1982-1998. Morbiditv and Mortalitv Weekly Report 50, 1-16.

POWA 2007: (http://wwwpowa.co.za/ msg/aspBoardDetail.asp?.d=48 Accessed 12 April 2007.

REED, FC 2003: Suffering from illness: Insights for caregivers. Philadephia, PA: Davis

ROBERTS, AR 1987: Psychosocial characteristics of batterers: A study of
234 men charged with domestic violence offenses. Journal of Family Violence. 2(1): 81-93.

ROBERTS, AR 2002: Myths, facts, and realities regarding battered women and their children: An overview. (In Roberts, AR, eds. 2002: Handbook of domestic violence intervention strategies. New York: Oxford University Press, p. 3-22).

ROBERTS, AR 2005: Bridging the past and present to the future of crisis intervention and crisis management. (In Roberts, AR, eds. 2005: Crisis intervention handbook: Assessment, treatment and research. New York: Oxford University Press, p.3-34).

ROBERTS, AR \& ROBERTS, BS 2005: Ending intimate abuse: Practical guidance and survival strategies. New York: Oxford University Press.

THOMPSON, MP; KASLOW, NJ \& KINGREE, JB 2002: Risk factors for suicide attempts among African American woman experiencing recent intimate partner violence. Violence and Victims. 17, 283-295.

TJADEN, P \& THOENNES, N 2000: Extant, nature, and consequence of intimate partner violence: Findings from the National, Violence Against Women Survey. Washington, DC: National Institute of Justice, U.S. Department of Justice.

VALENTINE, PB; ROBERTS, AR \& BURGESS, AW 1998: The stress crisis continuum: Its applications to domestic violence. (In Roberts, AR, eds. 1998: Battered women and their families: Intervention strategies and treatment programmes. New York: Springer, p. 29-57).

WANG, Q 2006: Culture and the development of self-knowledge. Current Directions in Psvchological Science. 15 (4): 182-187.

WOOD, K \& JEWKES, R 1997: Violence, rape and sexual coercion: everyday love in a South African township. Gender \& Development. 5(2): 41-46. 